\title{
Obtaining transit information from users of a collaborative transit app: Platform-based
} and individual-related motivators

Sarker, Rumana Islam; Kaplan, Sigal; Anderson, Marie Karen; Haustein, Sonja; Mailer, Markus; Timmermans, Harry J.P.

\section{Published in:}

Transportation Research Part C: Emerging Technologies

Link to article, DOI:

10.1016/j.trc.2019.03.011

Publication date:

2019

Document Version

Peer reviewed version

Link back to DTU Orbit

Citation (APA):

Sarker, R. I., Kaplan, S., Anderson, M. K., Haustein, S., Mailer, M., \& Timmermans, H. J. P. (2019). Obtaining transit information from users of a collaborative transit app: Platform-based and individual-related motivators. Transportation Research Part C: Emerging Technologies, 102, 173-188.

https://doi.org/10.1016/j.trc.2019.03.011

\section{General rights}

Copyright and moral rights for the publications made accessible in the public portal are retained by the authors and/or other copyright owners and it is a condition of accessing publications that users recognise and abide by the legal requirements associated with these rights.

- Users may download and print one copy of any publication from the public portal for the purpose of private study or research.

- You may not further distribute the material or use it for any profit-making activity or commercial gain

- You may freely distribute the URL identifying the publication in the public portal 


\section{Obtaining transit information from users of a collaborative transit app: platform-based and individual-related motivators}

Rumana Islam Sarker ${ }^{a^{*}}$, Sigal Kaplan ${ }^{\text {b }}$, Marie Karen Anderson ${ }^{c}$, Sonja Haustein ${ }^{\text {c, }}$, Markus Mailer ${ }^{\text {a }}$, Harry J.P. Timmermans ${ }^{\mathrm{d}}$

${ }^{\text {a }}$ Department of Infrastructure Engineering, University of Innsbruck

Technikerstrasse 13, 6020, Innsbruck, Austria

${ }^{\mathrm{b}}$ Department of Geography, Hebrew University of Jerusalem

Mt. Scopus, 919051, Jerusalem, Israel

${ }^{\mathrm{c}}$ Department of Management, Technical University of Denmark

2800 Kgs. Lyngby, Denmark

${ }^{\mathrm{d}}$ Department of the Built Environment, Eindhoven University of Technology

5600 MB Eindhoven, The Netherlands

Department of Air Transportation Management, Nanjing University of Aeronautics and Astronautics, 211106 Nanjing, China

${ }^{*}$ Corresponding Author

Department of Infrastructure Engineering, University of Innsbruck

Technikerstrasse 13, 6020, Innsbruck, Austria

Tel: +43-512-50762407; Fax: +43-512-50762498; Email: rumana.sarker@uibk.ac.at 


\begin{abstract}
The traditional practice of transit information provision considers operators as active communicators of information, while transit users are considered as passive, only receiving information. Encouraging reciprocity and active involvement of users by enabling them to share information may increase transit information quality and ridership. Nowadays, active user participation is starting to take shape with the development of new apps with commercial market potential. This study focuses on willingness to share travel information as part of daily routine transit app use. The applied behavioral framework is the Unified Theory of Acceptance and Use of Technology adapted to the context of information sharing. The empirical analysis consists of estimating a structural equation model on a data set including 1,369 people from Innsbruck and Copenhagen as cities differing in size and general social trust. The results show that the most important motivational factors for information sharing are pro-sharing social norms and self-actualization weighted against effort expectancy, which is more closely related to the logistic effort of using the platform than to network familiarity. Trust in the information provided and social network engagement are secondary motivational factors, with perceived information quality and need of communication being less influential. Greater transit use and interest in level-of-service and real-time information are correlated with greater information sharing motivation. Women and generation $\mathrm{Z}$ had higher motivation for information sharing as well as people who reside in Denmark, a country with high social trust.
\end{abstract}

Keywords: transit; collaborative travel; smartphone app; information sharing

\title{
1. Introduction
}

With transit operators increasingly adopting systems for collecting passenger data, social media and smartphone apps offer a new opportunity for collaborative information exchange and active user participation. The success of collaborative exchange is rooted in the concept of collective intelligence for uncovering creative solutions, and is aligned with public participation programs in urban planning (Brabham, 2012). Smartcard data analysis is already showing the benefits of crowdsourcing (Pelletier et al., 2011; Amaya et al., 2018), but active information sharing by travelers has additional merits. For transit providers, the benefits are improving infrastructure and service information, resolving the limitations of traditional mobility surveys, bettering realtime (RT) updates, increasing the coverage of short distance trips, retrieving more accurate route choice, and tracking multi-modality (Berger and Platzer, 2015; Costa et al., 2016). Collective knowledge can greatly contribute to dynamic planning processes that allow users to maximize their utility from the real-time information and feedback as well as detect the gaps in the system (Chaves et al., 2011). For example, it could reveal a better portrayal of transit users' travel experience and how in-vehicle and out-of-vehicle time, reliability, and incidents shape travelers recurrent choices (Carrel et al., 2015). Peer-to-peer information exchange, crowdsourcing, and the internet of things can not only be beneficial for dynamic route assignment and autonomous vehicles, but also for more efficient transit use (Ben-Elia and Avineri, 2015; Nunes et al., 2016). Currently, there are expectations that peer-to-peer travel information could be a useful tool for promoting knowledge regarding sustainable travel, and inducing behavioral change through persuasive techniques (Ben-Elia and Avineri, 2015; Attard et al., 2016; Andersson et al., 2018). In the era of lean production and public funding reductions, 
transit users are valuable partners in system design, fostering bottom-up development, and offering ideas for entrepreneurship and innovation (Filippi et al., 2013). Last, from the passenger perspective, interactivity is one of the strongest predictors of mobile app engagement, and consumers seek reciprocal and interactive experiences with their preferred apps (Kim and Baek, 2018) because higher traveler engagement is associated with enjoyment, social interaction, user empowerment, and self-actualization (Costa et al., 2016; Sun et al., 2017).

Recent studies show the potential of crowdsourcing to improve transit planning. Chaves et al. (2011) showed that transit users are sharing transit events from social networks, and are willing to use apps that enable such information sharing. Kim et al. (2014) discuss the benefits of incorporating social interactions in the mathematical framework of non-linear utility functions. Carrel et al. (2015) show that smartphone and vehicle location data can be used to quantify transit travel experiences. Gu et al. (2016) show that mining Twitter information is an efficient and cost-effective manner to widen the coverage of traffic incidents on highways and arterial roads. Cottrill et al. (2017) investigated Twitter usefulness for improving travel experience during a large event, and their findings indicate the potential of producing a more effective network of communication with passengers. Nunes et al. (2016) show that crowdsourced transit user information from the Andante automated fare collection (AFC) system in Porto showed that temporary user networks (TUN) can be generated on the basis of affinity as spatio-temporal dependent ties between transit users. According to their study, social networks of up to 40 "friends" per member can be generated based on route relevance comprised of similarity and substitutability, and can serve as a means for travel information exchange between users. Yildirimoglu and Kim (2018) used smart-card data to reveal community structures and activity pockets based on passenger trajectories. Zhang et al. (2018) investigated the effect of social interaction information from friends on commuters' daily route choice decisions. By developing a route-choice learning model with friends' travel information based on the Prospect Theory, the study shows that besides the actual route travel time shared among friends, the amount and share of friends choosing each route are influential. Currently, some travel app platforms include car-pooling options, and allow for chats among registered users. The new concept of "Mobility-as-a-Service” including multi-modal apps with personalized accounts offers opportunities to generate TUN and on-line communities based on passive crowd sourcing data and active willingness to share information through social networks. Moreover, TUN and information sharing across transit users could result in developing the emerging concepts of mobility-on-demand ride-sourcing services, and customized bus services that aim to provide efficient services for groups of commuters with similar travel demands (Liu et al., 2019; Lyu et al., 2019; Yan et al., 2018). The studies of Nunes et al. (2016), and Yildirimoglu and Kim (2018) addressed the passive data collection side and its potential for generating social networks among users who travel along the same route but do not know each other. Liu et al. (2019), and Lyu et al. (2019) propose a framework for supply-side planning and optimization. Yan et al. (2018) show what information would be most valuable to travelers seeking such opportunities. Our study adds to the body of knowledge by addressing willingness to share information as an important pillar supporting the success of such ventures.

Dual-mode user-operator transit information sharing platforms are still in their infancy and there is little information regarding their acceptance and use. Filippi et al. (2013) propose a platform in which users will be able to request and receive information from operators as well as share their needs and choices with other travelers. Miller (2013) provides a future vision of cooperative transport where operators and users share, collaborate, and act collectively 
regarding mobility and accessibility problems at operational and strategic levels. Nunes et al. (2014) suggests sharing a common platform among users and operators to receive service feedback with rewards for users who share information. Heiskala et al. (2016) analyzes crowdsourcing-based transportation services with the business model of a two-sided market. Nowadays, active user participation is starting to take shape with the development of new apps with commercial market potential. Tomasic et al. (2014) developed the app 'Tiramisu' from 2011-2014 for crowdsourcing bus arrival times, and offer a technological platform to increase participation rates. Hara et al. (2015) designed a tool for crowdsourcing bus-stop characteristics to improve transit accessibility for visually impaired travelers. The app 'OneRide' invites transit users to provide a feedback rating per trip regarding crowding, noise, reliability and cleanliness, and the ability to share the rating with other users (Costa et al., 2016). The application programming interface RideTap offers third-party developers the ability to integrate various transportation services into the 'Moovel' multi-modal app (Shaheen et al., 2017). ContriSense helps commuters plan their bus journey based on crowdsourcing smartphone data (Nandan et al., 2014). 'Moovit' is an early pioneer of Mobility as a Service (MaaS) and the developer of a free public transit app. The developer's website states that it has more than 300 million registered users in over 2,600 cities in 85 countries. 'Moovit' uses both passive crowdsourcing of traveler-sensed data to improve transit route schedule predictions, and active user reports of incidents and vehicle crowding (Heiskala et al., 2016). 'Moovit' amasses four billion anonymous data points a day to add to the world's largest repository of transit data. Moovit's network consists of more than 450,000 local editors called "Mooviters", who support the data gathering. These users help map and maintain local transit information in cities that would otherwise be unserved (Moovit, 2019).

Exploring willingness to share on-line information is key to determining the future of collaborative exchange, both for passive and active crowdsourcing. While the first steps in collaborative mobile apps are the open data approach and development of adequate sharing platforms, the final step consists of empowering users to share information (Filippi et al., 2013). A sufficiently large user base, and the willingness to share travel experiences and sensory information are the two main success factors for travel apps based on collaborative information exchange (Farkas et al., 2015). However, information exchange often exhibits the characteristics of a social dilemma. In some situations, the best approach from an individual perspective is to use data without reciprocity, while from the social perspective this strategy leads to the demise of the collaborative exchange effort (Kimmerle and Cress, 2013; Dickinson et al., 2015). Information sharing in a unique nation-wide 'grand' event of a transit design context was investigated by Brabham (2012), who found that participation is associated with career advancement, peer recognition, self-expression, learning of new skills, and having fun. However, daily information sharing on a transit app is a repetitive 'grey' task with benefits being better information quality and small rewards such as 'likes' from other users. Thus, understanding travelers' willingness to use transit apps in dual mode, both as information consumers and providers, will enable the design of collaborative travel apps to be improved.

In the literature, travel information is mainly treated as a travel resource streaming from the operators as providers to transit passengers as consumers. Molin and Timmermans (2006), Dickinson et al. (2015), Schmitz et al. (2016), Khoo and Asitha (2016), and Velazquez et al. (2018) focused on the motivation for smartphone app adoption and use. Farag and Lyons (2012) addressed the choice to use pre-trip travel information for long-distance leisure and business trips as a function of information quality, social norms, travel behavior, and attitudes. Chorus 
et al. (2007), Grothenhuis et al. (2007), and Hounsell et al. (2016) addressed information needs and expectations underlying information consumption. Kaplan et al. (2017) showed the high value of information under conditions of both low and high service quality. Chorus et al. (2009), Amaya et al. (2018), and Ben-Elia and Avineri (2015) investigated the impact of information on travel and transit use. Andersson et al. (2018) explored behavioral change through information provision, and Dastjerdi et al. (2019) investigated the willingness to use a travel information app that induces a behavioral change towards green travel behavior.

This study focuses on platform-related and individual-related barriers and motivators to share information as part of daily routine transit app use. Information exchange as a new concept largely relies on the willingness of travelers to share information on a regular basis (Costa et al., 2016), and user engagement is strongly needed for active information sharing and visualization tools (Farkas et al., 2015). While cost, battery consumption, and smartphone penetration rate are largely resolved, the user-technology interface remains the main challenge for app use as a crowdsourcing method for data collection in transportation (Nitsche et al., 2014; Gadziński, 2018). Information sharing can take two forms - passive and active. Passive information is based on apps collecting user data in the background, whereas active sharing is when the user takes action to share information. An example of the first is an app collecting location data and routes, while the second is complaining about crowdedness or delays. While silent background data collection is useful for collecting travel trajectories and time (Carrel et al., 2015), user travel satisfaction, incident reporting, and service quality feedback are the only means of encompassing the full scope of the passenger travel experience. This study is the first to address travel app use for voluntary active information sharing rather than receiving information. Dickinson (2015) identified poor functionality, lack of need, reluctance to take the first step, the existence of 'free riders', lack of a sense of community, and subjective time pressure as barriers to collaborative travel app engagement. In contrast, the current study addresses the case of a fully developed, widespread app with good functionality, and a legitimate choice between being part of a community or a 'free rider'. This study is the first to adapt the Unified Theory of Acceptance and Use of Technology (UTAUT) to the context of travel information sharing (Venkatesh et al., 2003). The model provides a comprehensive and rigorous behavioral framework that relates information sharing to performance and effort expectancy, social norms, and facilitating conditions. The model is validated by results from a large-scale survey conducted in Austria and Denmark, showing the empirical validity of the proposed framework.

The paper is organized as follows. The next section details the behavioral framework, survey design, and statistical analysis. Section 3 presents the sample characteristics and model estimation results. The last section offers discussion and conclusions.

\section{Methods}

\subsection{The proposed behavioral framework}

The hypothesized framework is a modified version of the UTAUT (Venkatesh et al., 2003) adapted to the context of information sharing on a transit app. The original model, presented in Figure 1, was applied to the context of information technology use at work. Previously, a slightly different version of the UTAUT, namely the Technology Acceptance Model (TAM), was applied to transit mobile payment app acceptance (Di Pietro et al., 2015), to understand intentions to use transit apps (Schmitz et al., 2016), and quantify the effect of information on transit use (Kaplan et al., 2017). While the TAM fundamental constructs do not 
fully reflect the influence of technological and contextual factors underlying user acceptance, the UTAUT has been augmented with various human (internal) and policy (external) factors that may further influence the adoption decision (Venkatesh et al., 2016; Panagiotopoulos and Dimitrakopoulos, 2018). This study is the first to apply the extended UTAUT framework to the context of information sharing. The original application of the model to the context of the repetitive daily use of information technology without incentives apart from the quality of work and peer recognition is similar to the context of on-line information sharing as part of the daily travel routine. In accordance with the UTAUT, we hypothesize that information sharing intentions are related to performance and effort expectancy, social norms, and facilitating conditions. Within this framework, we considered an extended version of the UTAUT including trust, familiarity, perceived appreciation, social influence, self-actualization, involvement, and knowledge sharing. Notably, according to the UTAUT, the antecedents are independent and directly linked to the behavioral intention of technology use.

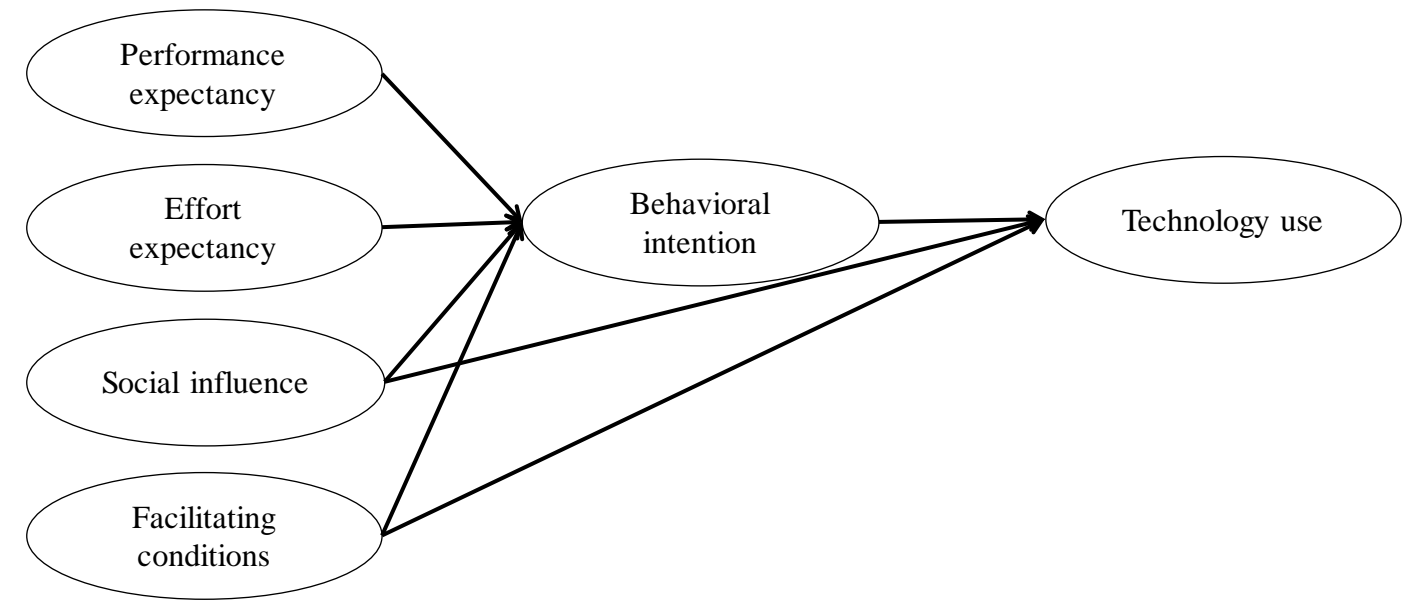

Figure 1: The original Unified Theory of Acceptance and Use of Technology (source: Venkatesh et al., 2003)

Performance expectancy relates to the relative advantage and outcome expectations. In the context of travel information sharing, we postulate that performance expectancy is related to the perceived quality of information provided by the system, and the perceived trust in the information shared by other users. Similarly to Panagiotopoulos and Dimitrakopoulos (2018) perceived information quality, and trust in the shared information are considered as two independent latent constructs. Information quality is an outcome expectation, and provides a relative advantage to the system users, while trust in the information provided by other users can be interpreted as related to the perceived reliability of information sharing. Because better app performance means time savings and seamless travel, within the context of goal-driven behavior performance expectancy, this is related to the gain perspective (Lindenberg and Steg, 2007).

Effort expectancy is defined as the degree of ease of use of the system, but may also depend on individual knowledge and competence. Thus, we extend the notion of effort expectancy to include both ease of use and system familiarity. We postulate that, in the context of knowledge sharing, the system's ease of use relates to time consumption, complexity, memory, and the need for an on-line connection. Individual competence depends on familiarity with the transit system, which decreases the effort associated with information provision. 
Social influence is often represented as conforming to social norms. However, in the context of information sharing and the era of social networks, social influence can also be related to social engagement, involvement, and knowledge sharing. Thus, we extend the notion of social influence to include both social norms and self-actualization, namely the positive feeling associated with contributing to helping others and thus the greater good. In this context, self-actualization is defined as goal-driven behavior of acting according to ones' core values of knowledge sharing, social engagement, and involvement. An important determinant of goaldriven behavior is from the normative perspective of doing right, and from the hedonic perspective of feeling good about oneself (Lindenberg and Steg, 2007). Perceived appreciation from the operator and other transit users responds to the need for social feedback and support from important others. While perceived appreciation does not appear in the original UTAUT model, it is relevant within the current context of information sharing because transit operator feedback, and recognition from other users are expected responses to user-based information sharing as part of a general team climate. In the context of information exchange, we add the need of communication to the realm of social needs because it drives people to share their thoughts and feelings with others. In this study, the need of communication is quantified by the frequency of face-to-face, phone, and text communication.

Facilitating conditions are defined in the original model as the degree to which an individual is aware of the existence of a technological or organizational platform to support behavior. We hypothesize that the frequency of social network engagement online can serve as an indicator of the belief in the value of a technological platform that supports information sharing.

The following research hypotheses stem from the behavioral framework:

1. H1: Better information quality, and greater trust in the information provided are associated with greater information sharing intention;

2. H2: Stronger social norms for information sharing are related to stronger information sharing intention;

3. H3: Greater familiarity with the transit system, and greater perceived system ease of use are correlated with greater information sharing intentions;

4. H4: Higher social network engagement relates to greater willingness to share information;

5. H5: Higher sense of self-actualization by sharing is related to greater information sharing intentions;

6. H6: Greater need of communication is associated with higher information sharing intentions.

\subsection{Survey design and administration}

The data for investigating the research hypotheses were collected using a tailor-made web-based questionnaire eliciting the intentions to receive and share information on a popular mobile app that enables user engagement, and 'Moovit' was provided as an example of an app widely available in Europe. 
The current user experience of transit information, which is based on operator-users unidirectional information flow, was elicited by asking respondents about their current frequency of transit app use, and their perceived transit information quality.

Respondents were asked about their willingness to use a transit app that allows information sharing on a regular basis and to share information, their preferred theme, and their preferred frequency of sharing information. As a control, each question elicited the same preferences for receiving information. The frequency for sharing and receiving information was assessed on a 5-point Likert scale ( 1 = "never"; 5 = "always") and varied between rarely (2) and always. The respondents were asked whether or not they would like to receive/ share information about the following themes: level of service (e.g. arrival times, delays, crowding), facilities (cleanliness, design, and conditions), behavior of transit personnel (e.g. courtesy, friendliness, and empathy), perceived injustice or discriminatory behavior, and real-time information.

The eight factors hypothesized to be correlated to information sharing are information quality, trust in the information provided by other users, network familiarity, social norms of information sharing, need of communication, self-actualization for sharing information, social network engagement, and perceived difficulty in sharing information.

Information quality concerned ease of finding information, clarity and completeness, reliability of travel times and delay notifications, and the provision of efficient routes. Trust in the information provided by others addressed both the information source, and the type of information provided. Firstly, respondents were asked about their trust in informal or unverified information sources (e.g. social media, other transit users) versus transit operator provided information. Secondly, respondents were asked about trusting other transit users to provide the following information categories: level-of-service (LOS), congestion and crowding, alternative routes, and answers to specific questions or requests.

Transit network familiarity included perceived familiarity with lines, timetables and stops as well as the perceived ability to arrive at new destinations. Information sharing social norms were quantified by perceived appreciation from the operator, other transit users, and one's own social network, as well as a perceived sense of community belonging and togetherness achieved by information sharing. The need of communication was captured by the frequency of use of various communication methods: face-to-face, voice calls, and text messaging. Self-actualization by sharing information consisted of questions related to positive feelings and enjoyment in helping others, and the perceived benefit to other transit users. Social network engagement was captured by the current frequency of on-line posting activities. Perceived difficulties in sharing information included time consumption, associated mental effort and forgetfulness, and difficulties being online while travelling.

Responses were elicited using a 5-point Likert scale ranging from "strongly disagree (1)" to "strongly agree (5)". A balanced questionnaire design including both positively and negatively phrased items was chosen as a well-established and widely-used coping strategy with compliant responding, namely the tendency to agree with the questionnaire items. Reverse scoring was applied as the standard procedure in the data analysis to combine the negatively and positively phrased items.

A respondent's socio-economic characteristics (e.g. age, gender, residential arrangements, employment, smartphone access, etc.) were used as control variables. The survey 
targeted young millennials or "digital natives" due to their social media use for information, socializing, and experiencing a sense of community as well as their familiarity with collaborative transport consumption, and on-line sharing practices of tangibles and intangibles such as ideas, values, and time (Belk, 2014). Gen Y or millennials (defined as those born between 1981 and 1990) stay connected online and multitask through technology, spend considerable time consuming content, sharing, contributing, and participating in on-line communities with high intensity. A recent survey showed that $80 \%$ of millennials perform daily on-line social networking and information search activities (Moráis et al., 2017). Millennials also exhibit the social dilemma for on-line sharing. While millennials are accustomed to usergenerated apps, on-line reviews, and spreading e-word-of-mouth (e-WOM), information consuming is far more pronounced than information sharing (Bolton et al., 2013).

The survey was administered in June 2016 in Danish, English, and German targeting undergraduate and graduate students of the University of Innsbruck in Austria and the Technical University of Denmark in Lyngby (part of Greater Copenhagen ${ }^{1}$ ) through mailing lists and university networks. The choice of targeting young adults, particularly students, derives both from the travel perspective and the student voice perspective. From the travel perspective, data shows a decrease in car ownership and driving licenses among young people. In Britain for example, $29 \%$ of $17-20$ year olds and $63 \%$ of $21-29$ year olds had a driving license in 2014, compared to much higher numbers (i.e., 48\% and 75\%) in 1992/94 (Chatterjee et al., 2018). Thus, better transit service is important to maintain mobility and travel independence among the younger cohorts. From the ‘student voice’ perspective, encouraging young people to express their concerns and expectations, and to take action to induce change is considered a powerful contribution to building citizenship through the development and renewal of civic society practices (Fielding, 2004). Because transit is one of the main travel modes of university students, they have both first-hand experience and personal motivation to take action. According to the literature review by Sujithamrak and Lam (2005), studies show that younger, better educated, and higher income individuals submit complaints more than other customers do. Thus, students have better prospects to share information regarding transit level of service compared to other captive transit user groups (e.g., elderly and low-income groups), and their voice can also serve to improve transit for less-privileged passenger groups. Notably, a limitation deriving from focusing on young adults is that the survey results cannot be generalized to all transit users or other population groups, which are significantly different in their on-line activity patterns. Another data limitation is that this study is based on crosssectional data, namely on the difference between individuals, and hence cannot be used to predict changes within the behavior of any given individual, which precludes various avenues for policy design. For policy design, the approach taken by Dickinson et al. (2015) and Velasquez et al. (2018) of before and after actual app use is preferred. Nevertheless, such a before and after study can only be conducted if a beta version of the new technology is available at the time of the research. This is a common limitation when new technologies are in their nascent stage.

Innsbruck and Copenhagen have integrated transport systems with RT information, but they differ in their size, and hence possibly in their need to receive and share information. Copenhagen's population comprises over half a million inhabitants, and its transport system includes roughly 500 bus, rail and metro lines, while Innsbruck has circa 125 thousand

\footnotetext{
${ }^{1}$ To improve readability of this paper, we refer to Copenhagen in the following parts of this paper, though not all Danish survey participants live in Copenhagen; similarly, not all Austrian participants live in Innsbruck.
} 
inhabitants, and only 24 bus lines and 3 tram lines. The two cities also differ in their ranking of social trust in other people because greater social trust is found in Denmark than in Austria (Newton, 2002; Boelhouwer et al., 2016), which may also affect willingness to share information. As social trust in Denmark is higher, and Denmark has strong norms for collaborative solidarity (Sørvoll and Bengtsson, 2018), we hypothesize stronger social norms for sharing and greater trust in the information provided in Copenhagen compared to Innsbruck. Accessibility to technology is not a barrier because, according to Austrian Statistics, 97\% of Austrians above 10 years of age have internet access. The questionnaire took about 10 minutes to complete with the opportunity to participate in a raffle of 12 gift cards containing an entrance ticket to leisure activity centers in Austria and 8 purchase vouchers in Denmark.

\subsection{Statistical analysis}

A structural equations model (SEM) served for the estimation of the relation between the intentions to share information, and hypothesized motivational factors. The model contains measurement equations linking latent motivational factors to observed indicators (eq. 1), structural equations linking latent factors to individual characteristics (eq. 2), and structural equations relating motivational factors to information sharing intentions (eq. 3).

$$
\begin{gathered}
I_{d n}=Z_{l n}^{*} \alpha_{d}+v_{d n} \quad \text { and } \quad v_{n} \square N\left(0, \Sigma_{v}\right) \quad \text { for } d=1, \ldots, D \\
Z_{l n}^{*}=S C_{l n} \beta_{l}+\omega_{l n} \quad \text { and } \quad \omega_{n} \square N\left(0, \Sigma_{\omega}\right) \quad \text { for } l=1, \ldots, L \\
R_{i n}^{*}=Z_{l n}^{*} \beta_{r}+\xi_{\text {in }} \quad \text { and } \quad \xi_{n} \square N\left(0, \Sigma_{\xi}\right) \quad \text { for } i=1, \ldots, I
\end{gathered}
$$

Where $\mathrm{Z}^{*}$ In is the value of latent construct $\mathrm{l}$ for individual $\mathrm{n}, \mathrm{I}_{\mathrm{dn}}$ is the value of an indicator $\mathrm{d}$ of the latent construct $Z^{*} \ln , S C_{\ln }$ is a vector of socio-economic characteristics, and $\mathrm{R}_{\text {in }}$ is a vector of information sharing intentions. Error terms are expressed as elements $v_{d n}$, $\omega_{\text {ln }}$, and $\xi_{\text {in }}$ of the vectors following a normal distribution with respective covariance matrices $\Sigma_{\omega}, \Sigma_{v}$, and $\Sigma_{\xi}$, while parameters to be estimated are $\alpha_{d}, \beta_{l}$, and $\beta_{r}$. There are $D$ measurement equations which lead to the estimation of a $(D \times 1)$ vector $\alpha$ of parameters. $L$ latent constructs translate into estimating an $(M \times L)$ matrix of $\beta$ parameters.

The model was estimated using M-Plus. The parameters were estimated simultaneously by using Maximum Likelihood with Huber-White covariance adjustment. The standard errors from White's sandwich-based estimator produce robust statistics in the presence of nonnormality of the indicators and categorical variables. The goodness of fit was evaluated using the traditional descriptive measure of chi-square test of model fit (CFI), and Root Mean Square of Approximation (RMSA). 


\section{Results}

\subsection{Sample characteristics}

In total, the survey included 1,369 complete responses (53\% from Copenhagen). In Copenhagen, the majority of participants are men (62\%), in Innsbruck women (55\%), and more participants in Copenhagen live alone (33\% vs. 19\%). Despite these differences in demographics, the residential sharing patterns, daily rhythm, smartphone use, transit use, and transit information search in Innsbruck and Copenhagen are very similar (see Table 1).

\begin{tabular}{|c|c|c|c|c|c|}
\hline Variable & Categories (\%) & & & & \\
\hline \multirow[t]{2}{*}{ Gender } & Male & Female & & & \\
\hline & 54 & 46 & & & \\
\hline \multirow[t]{2}{*}{ Age } & $18-20$ & 21-25 & $26-30$ & 31-35 & $>35$ \\
\hline & 10 & 53 & 19 & 7 & 11 \\
\hline \multirow[t]{2}{*}{ Residence } & Alone & Friends & Parents & Partner & $\begin{array}{l}\text { Partner } \\
\text { children }\end{array}$ \\
\hline & 26 & 32 & 12 & 21 & 9 \\
\hline \multirow[t]{2}{*}{ Employment } & Studying & Working & Both & None & \\
\hline & 41 & 13 & 45 & 1 & \\
\hline \multirow[t]{2}{*}{ Activity } & Hectic & Active & Relaxed & & \\
\hline & 10 & 72 & 18 & & \\
\hline \multirow[t]{2}{*}{ Smartphone } & No & Yes & & & \\
\hline & 9 & 91 & & & \\
\hline \multirow[t]{2}{*}{ Transit use } & Once a month & $\begin{array}{l}2-3 \text { times } \\
\text { monthly }\end{array}$ & Once a week & $\begin{array}{l}\text { 2-4 times } \\
\text { weekly }\end{array}$ & Daily \\
\hline & 8 & 16 & 16 & 25 & 35 \\
\hline \multirow[t]{2}{*}{ Transit info search } & Once a month & $\begin{array}{l}2-3 \text { times } \\
\text { monthly }\end{array}$ & Once a week & $\begin{array}{l}\text { 2-4 times } \\
\text { weekly }\end{array}$ & Daily \\
\hline & 15 & 22 & 22 & 26 & 15 \\
\hline
\end{tabular}

Table 1: Overall Sample Characteristics

Figure 2 presents respondents' intentions to receive and share information, and reveals that the distribution of receiving and sharing intentions is similar across the two cities despite their difference in size. In agreement with other studies, respondents were more willing to receive than to share information. While almost half of the respondents were willing to receive information often, only one-sixth of the respondents were willing to share information to the same extent. However, one-third of the respondents were willing to share information on an occasional basis. Table 2 shows that respondents' willingness to receive and share information varies by theme. The most popular information needs by far were LOS and RT information, while only one-third of the respondents were interested in receiving information about tangibles or discrimination, and with the least popular theme being personnel behavior. Concerning information sharing, one-third of the respondents were willing to share information about LOS, $\mathrm{RT}$, and discriminatory behavior. Roughly one-quarter of the respondents were willing to share information regarding tangibles and personnel behavior. 


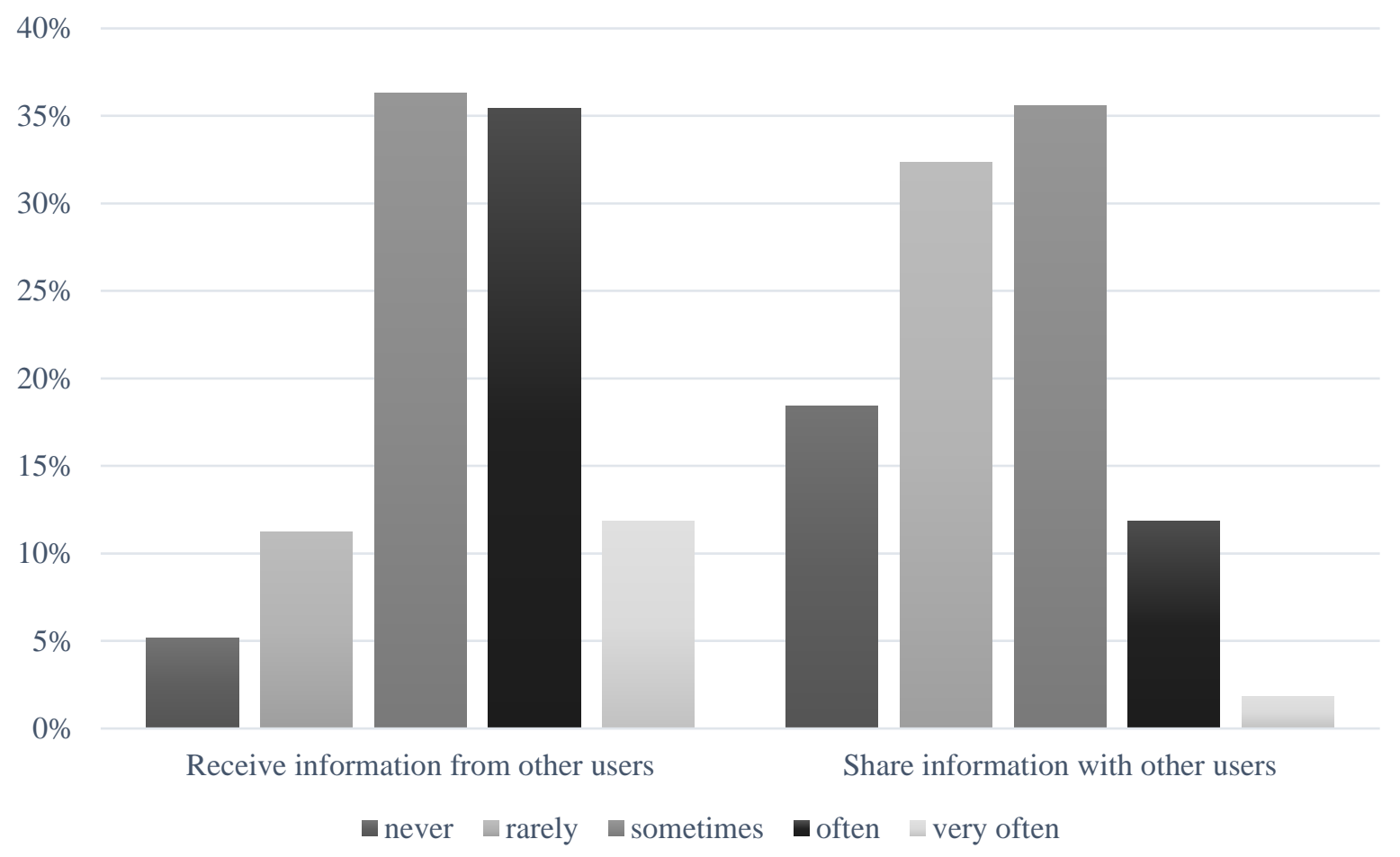

Figure 2: Frequency of using transit app for sharing/receiving information

\begin{tabular}{|l|l|l|l|l|}
\hline Information (overall sample) & $\begin{array}{l}\text { Receive } \\
\mathbf{( \% )}\end{array}$ & $\begin{array}{l}\text { Share } \\
\mathbf{( \% )}\end{array}$ & $\begin{array}{l}\text { None } \\
\mathbf{( \% )}\end{array}$ & $\begin{array}{l}\text { Total } \\
\mathbf{( \% )}\end{array}$ \\
\hline LOS (e.g. arrival times, delays, crowding, accidents) & 58 & 34 & 8 & 100 \\
\hline Condition of the vehicles and stations (e.g. cleanliness, damage) & 37 & 23 & 40 & 100 \\
\hline Personnel (e.g. courtesy, friendliness, competences) & 28 & 24 & 48 & 100 \\
\hline Unequal treatment (e.g. discrimination, price differences) & 33 & 36 & 31 & 100 \\
\hline RT information to/from other passengers & 53 & 31 & 16 & 100 \\
\hline
\end{tabular}

Table 2: Willingness of the transit users to receive/share the following information

\subsection{Model estimation results}

The analysis included exploratory factor analysis followed by an SEM estimation. The sample validity, reliability, and adequacy were tested and confirmed using Cronbach's alpha = 0.844 and KMO (Kaiser-Meyer-Olkin) $=0.858$, confirming its suitability for factor analysis and SEM estimation. The factors were extracted by Principle Axis Factoring because it is distribution free and accommodates both normality and non-normality. Varimax rotation was applied to form the orthogonal solution. The KMO item statistics, factor loading, and communalities are provided in the table in Appendix 1. The KMO values are within the required range, well above 0.6, and the communalities are medium within the range of 0.4-0.7 for most items. While the communalities of the items for the perceived difficulty of use are lower, the confirmatory factor analysis shows that the item correlations are statistically significant. Despite the lower communalities, the factor "difficulty of use" was included due to its theoretical and empirical importance.

The estimated model for information sharing intentions shows excellent goodness of fit (CFI=0.887), and Root Mean Square of Approximation within the acceptable range (RMSA=0.048). Table 3 presents the measurement equations representing the factor analysis. 


\begin{tabular}{|c|c|c|}
\hline Information quality & est. & t-stat \\
\hline The travel time/waiting time information is reliable & 1.000 & - \\
\hline The information about delays/changes is reliable & 0.949 & $29.70^{* * *}$ \\
\hline The information system provides efficient routes & 0.769 & $25.37^{* * *}$ \\
\hline The information is clear and comprehensible & 1.120 & $36.83^{* * *}$ \\
\hline The information is easy to find & 1.029 & $34.76^{* * *}$ \\
\hline Familiarity & est. & t-stat \\
\hline The frequency of lines I need & 1.000 & - \\
\hline How to arrive at new destination & 1.006 & $25.38^{* * *}$ \\
\hline Transit stops closest to my destination & 1.122 & $25.49^{* * *}$ \\
\hline Timetable of modes that I use most & 1.058 & $25.10^{* * *}$ \\
\hline The bus / train lines in my local area & 0.801 & $19.38^{* * *}$ \\
\hline Perceived difficulty of use & est. & t-stat \\
\hline It would be too time consuming for me & 1.000 & - \\
\hline I would often forget to share important information & 0.571 & $14.44^{* * *}$ \\
\hline It would be too much effort for me & 1.112 & $23.50^{* * *}$ \\
\hline It would be difficult because I am often not online when travelling & 1.143 & $24.33^{* * *}$ \\
\hline It would be difficult because my phone is often turned off while travelling & 1.059 & $22.29^{* * *}$ \\
\hline Self-actualization by sharing & est. & t-stat \\
\hline I gladly help others by providing information & 1.000 & - \\
\hline Most people find the information I share useful & 0.964 & $48.80^{* * *}$ \\
\hline It gives me a good feeling to share information even if people don't thank me & 1.038 & $58.85^{* * *}$ \\
\hline I share information so that others can benefit from my experience & 1.088 & $60.44^{* * *}$ \\
\hline It pleases me to be able to help others with information & 1.073 & $59.25^{* * *}$ \\
\hline Social norms of sharing & est. & t-stat \\
\hline Transit users would appreciate it & 1.000 & - \\
\hline Transit operators would be grateful & 1.043 & $15.11^{* * *}$ \\
\hline People who are important to me would encourage me to do it & 1.639 & $16.88^{* * *}$ \\
\hline It would make me feel part of the user community & 1.859 & $16.83^{* * *}$ \\
\hline It would expand my social network & 2.060 & $16.59^{* * *}$ \\
\hline I would feel connected to other users & 2.202 & $16.83^{* * *}$ \\
\hline Trust in the information provided & est. & t-stat \\
\hline I also trust information from people who I do not know & 1.000 & - \\
\hline Other passengers usually provide trustworthy information & 0.995 & $38.70^{* * *}$ \\
\hline I trust information shared by my virtual social network (e.g. Facebook friends) & 0.661 & $25.40^{* * *}$ \\
\hline Arrival times, traffic congestion, and delays & 0.809 & $33.03^{* * *}$ \\
\hline Available seats (e.g. empty seats, space for bicycle / pushchair) & 0.693 & $26.89^{* * *}$ \\
\hline Crowds during special events (e.g. football matches, music events) & 0.826 & $32.54^{* * *}$ \\
\hline Alternative routes (e.g. faster, cheaper) & 0.659 & $25.14^{* * *}$ \\
\hline Answers to my specific questions to other users & 0.659 & $25.91^{* * *}$ \\
\hline Need of personal communication & est. & t-stat \\
\hline I often engage in face-to-face communication & 1.000 & - \\
\hline I often conduct voice phone calls & 1.389 & $22.03^{* * *}$ \\
\hline I often use text messaging & 1.099 & $27.09^{* * *}$ \\
\hline Social network engagement & est. & t-stat \\
\hline
\end{tabular}




\begin{tabular}{|l|l|l|}
\hline I read other people's posts online & 1.000 & - \\
\hline I post my opinions online & 1.292 & $31.94^{* * *}$ \\
\hline I post if I do something interesting & 1.208 & $31.68^{* * *}$ \\
\hline I share what other people post & 1.164 & $30.18^{* * *}$ \\
\hline I comment and like others' posts & 1.216 & $30.13^{* * *}$ \\
\hline
\end{tabular}

Table 3: Measurement equations $\left(* 0.1\right.$ significance, ${ }^{* *} 0.05$ significance, ${ }^{* * * 0.001}$ significance)

\subsection{Individual characteristics underlying the motivational factors}

Table 4 presents the structural equations relating the motivational factors to socioeconomic characteristics.

Transit use More frequent transit use links to higher information sharing intentions due to motivational factors. Greater transit use relates to higher perceived information quality, greater familiarity with the system, higher self-actualization by sharing, greater trust in the information provided, and fewer perceived difficulties in information sharing. Transit use is also correlated with higher social network engagement suggesting multitasking on social media while travelling on transit.

Thematic interest in information sharing Greater interest in sharing more information relates to higher perceived information quality, greater familiarity with the system, higher selfactualization by sharing, greater trust in the information provided, and fewer perceived difficulties in information sharing. The themes that have the strongest relation to the motivational factors are LOS and RT updates, followed by facility conditions, and perceived discriminatory behavior. The need of personal communication is related only to sharing information regarding discriminatory behavior.

Social trust The city of residence served as a representation of the amount of general social trust in other people. Residence in Copenhagen compared to Innsbruck is related to higher social norms of sharing, and stronger trust in the information provided by other transit users, thus confirming our hypotheses. Residence in Copenhagen versus Innsbruck is also related to a higher need of personal communication, which can be a byproduct of social trust. A slight difference in the perceived difficulty of app use was also found between the two cities, possibly related to the difference in the difficulty in use of the existing transit information app in the two cities.

Socio-economic characteristics Gender differences are pronounced with male respondents reporting fewer difficulties in using the platform for sharing, but also less transit network familiarity, lower social network engagement, and less trust in the information provided by others. Hence, female as compared to male gender is a supporting factor in sharing information relative to male respondents. According to Sujithamrak and Lam (2005), female customers are more likely to complain compared to male customers. Hence, information sharing follows the same gender trend as consumer complaint behavior. With respect to age, the youngest cohort (under 18 years) reported greater trust in the information provided, higher social norms and higher self-actualization for information sharing, and the lowest effort expectancy. However, given the very young trend of the cohort overall, it is difficult to assess whether the effect is due to a generational effect or life stage. Living in a shared residential arrangement is related to higher self-actualization, greater trust in the information provided, and greater familiarity with the transit system. Having children is associated with lower social 
network engagement, probably due to greater time pressure when having children and studying/working.

\begin{tabular}{|c|c|c|c|c|c|}
\hline Information quality & est. & t-stat & Self-actualization by sharing & est. & t-stat \\
\hline 21-25 years old & 0.182 & $2.56^{* *}$ & $<18$ years old & 0.391 & $2.11^{* *}$ \\
\hline 26-30 years old & 0.135 & $1.91^{*}$ & Living with roommates & 0.133 & $2.22^{* *}$ \\
\hline 31-35 years old & 0.228 & $3.02^{* * *}$ & Living with spouse & 0.115 & $1.72^{*}$ \\
\hline Living with parents & -0.104 & $-1.95^{*}$ & Transit use 2/3 times monthly & 0.155 & $1.65^{*}$ \\
\hline Living with spouse & -0.130 & $-2.13^{* *}$ & Transit use once a week & 0.101 & 1.06 \\
\hline Active & 0.105 & $2.25^{* *}$ & Transit use 2/4 times weekly & 0.143 & 1.64 \\
\hline Transit use 2/4 times weekly & 0.161 & $1.83^{*}$ & Transit use daily & 0.191 & $2.25^{* *}$ \\
\hline Transit use daily & 0.211 & $2.45^{* *}$ & Share info -LOS & 0.387 & $6.67^{* * *}$ \\
\hline Share info - LOS & 0.135 & $2.55^{* *}$ & Share info - conditions & 0.242 & $3.97^{* * *}$ \\
\hline Familiarity & est. & t-stat & Share info - unequal treatment & 0.135 & $2.45^{* *}$ \\
\hline Male & -0.061 & $-2.13^{* *}$ & Share info - RT updates & 0.305 & $5.17^{* * *}$ \\
\hline Living with parents & 0.141 & $1.88^{*}$ & Social norms of sharing & est. & t-stat \\
\hline Living with spouse & 0.052 & $1.76^{*}$ & Austria & -0.128 & $-4.57^{* * *}$ \\
\hline Student & -0.740 & $-2.52^{* *}$ & $<18$ years old & 0.279 & $2.18^{* *}$ \\
\hline Worker & -0.633 & $-2.15^{* *}$ & Worker & -0.308 & $-1.74^{*}$ \\
\hline Student and worker & -0.686 & $-2.34^{* *}$ & Transit use once a week & 0.085 & $1.77^{*}$ \\
\hline Transit use 2/3 times monthly & 0.178 & $2.07^{* *}$ & Transit use 2/4 times per week & 0.046 & 1.57 \\
\hline Transit use once a week & 0.246 & $2.86^{* * *}$ & Transit use daily & 0.149 & $3.47^{* * *}$ \\
\hline Transit use 2/4 times weekly & 0.529 & $6.53^{* * *}$ & Share info -LOS & 0.180 & $5.81^{* * *}$ \\
\hline Transit use daily & 0.695 & $8.69^{* * *}$ & Share info - conditions & 0.125 & $4.03^{* * *}$ \\
\hline Share info - conditions & 0.108 & $1.93^{*}$ & Share info - personnel & 0.096 & $3.00^{* * *}$ \\
\hline Share info - unequal treatment & -0.150 & $-3.06^{* * *}$ & Share info - RT updates & 0.122 & $4.21^{* * *}$ \\
\hline Perceived difficulty of use & est. & t-stat & Trust in provided information & est. & t-stat \\
\hline Austria & 0.087 & $2.07^{* *}$ & Austria & -0.276 & $-4.93^{* * *}$ \\
\hline Male & -0.063 & $-1.66^{*}$ & Male & -0.144 & $-2.82^{* * *}$ \\
\hline$<18$ years old & -0.829 & -2.14 & $<18$ years old & 0.884 & $2.67^{* * *}$ \\
\hline 18-20 years old & -0.426 & $-3.49^{* * *}$ & $18-20$ years old & 0.455 & $2.54^{* *}$ \\
\hline 21-25 years old & -0.398 & $-3.72^{* * *}$ & 21-25 years old & 0.560 & $3.39^{* * *}$ \\
\hline 26-30 years old & -0.222 & $-2.13^{* *}$ & 26-30 years old & 0.408 & $2.50^{* *}$ \\
\hline 31-35 years old & -0.296 & $-2.72^{* * *}$ & 31-35 years old & 0.317 & $1.82^{*}$ \\
\hline $36-40$ years old & -0.293 & $-2.24^{* *}$ & Living with roommates & 0.162 & $2.53^{* *}$ \\
\hline Active & -0.144 & $-2.22^{* *}$ & Transit use 2/3 times monthly & 0.177 & $1.74^{*}$ \\
\hline Relaxed & -0.143 & $-1.96^{* *}$ & Share info -LOS & 0.265 & $4.57^{* * * *}$ \\
\hline Transit use once a week & -0.121 & $-2.52^{* *}$ & Share info - unequal treatment & 0.215 & $3.77^{* * * *}$ \\
\hline Transit use weekly & -0.057 & $-1.70^{*}$ & Share info -RT updates & 0.274 & $4.64^{* * *}$ \\
\hline Transit use daily & -0.096 & $-2.18^{* *}$ & $\begin{array}{l}\text { Need of } \\
\text { communication }\end{array}$ & est. & t-stat \\
\hline Share info - LOS & -0.390 & $-8.13^{* * *}$ & Austria & -0.131 & $-2.85^{* * *}$ \\
\hline Share info - treatment & -0.140 & $-3.18^{* * *}$ & Male & -0.144 & $-3.43^{* * *}$ \\
\hline Share info - RT updates & -0.311 & $-6.22^{* * *}$ & Relaxed & -0.131 & $-1.66^{*}$ \\
\hline Social network engagement & est. & t-stat & Transit use 2/4 times per week & -0.122 & -1.53 \\
\hline Male & -0.129 & $-3.15^{* * *}$ & Transit use daily & -0.160 & $-2.08^{* *}$ \\
\hline
\end{tabular}




\begin{tabular}{|l|l|l|l|l|l|}
\hline$<18$ years old & 0.687 & $2.40^{* *}$ & Share info - unequal treatment & 0.113 & $2.35^{* *}$ \\
\hline 18-20 years old & 0.512 & $3.44^{* * *}$ & & & \\
\hline $21-25$ years old & 0.624 & $4.55^{* * *}$ & & & \\
\hline 26-30 years old & 0.670 & $4.93^{* * *}$ & & & \\
\hline $31-35$ years old & 0.587 & $4.05^{* * *}$ & & & \\
\hline 36-40 years old & 0.505 & $3.24^{* * *}$ & & & \\
\hline Living with spouse and children & -0.159 & $-1.75^{*}$ & & & \\
\hline Transit use once a week & 0.166 & $2.00^{* *}$ & & & \\
\hline Transit use $2 / 4$ times per week & 0.174 & $2.20^{* *}$ & & & \\
\hline Transit use daily & 0.213 & $2.80^{* * *}$ & & & \\
\hline Share info - LOS & 0.150 & $3.06^{* * *}$ & & & \\
\hline Share info - personnel & 0.129 & $2.35^{* *}$ & & & \\
\hline Share info - unequal treatment & 0.181 & $3.77^{* * *}$ & & & \\
\hline Share info - RT updates & 0.168 & $3.36^{* * *}$ & & & \\
\hline
\end{tabular}

Table 4: Structural equations $\left({ }^{*} 0.1\right.$ significance, ${ }^{* *} 0.05$ significance, ${ }^{* * *} 0.001$ significance)

\subsection{The motivational factors related to information sharing intentions}

Figure 3 presents the path diagram relating the estimated relations between the platformbased and individual-based motivators, and the intention to share travel information on the online mobile transit app. The estimated relations are significant at the 0.05 significance level, and confirm research hypotheses H1-H6, as shown in the figure. While the use of information technology in a workplace setting is motivated mainly by performance expectancy (Schmitz et al., 2016), the results show that information sharing on a mobile app depends mainly on social norms and self-actualization weighted against effort expectancy. Our results show that greater trust in the information provided by others is related to higher intentions to share information, and that trust in the information provided is one of the important factors in information sharing, although it is secondary to social norms and self-actualization. In terms of effort expectancy, people are more concerned with the logistics of information sharing (time consumption, the need to be online) than with their transit network familiarity. Hence, the operational burden associated with the task of sharing information is more important than lack of network familiarity. While the need of communication is only of minor importance, regular social network engagement is of much higher value. 


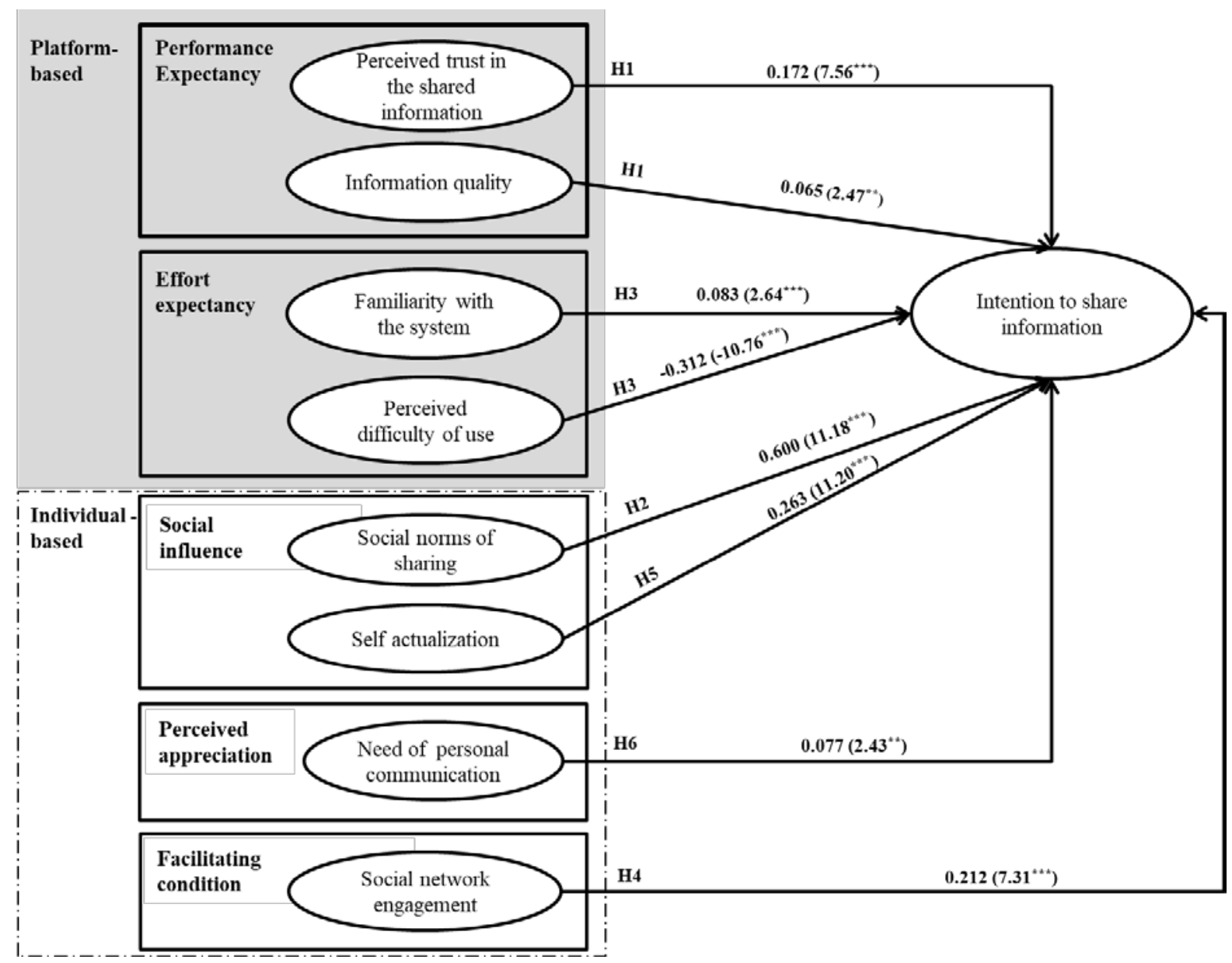

Figure 3: Information sharing intentions model $\left(* 0.1\right.$ significance, ${ }^{*} 0.05$ significance, $* * * 0.001$ significance)

\subsection{Correlation across the latent variables}

Table 5 presents the estimated correlation matrix between the latent variables in the current model. The unified theory of technology acceptance and use (UTAUT, Venkatesh et al., 2003) as well as its extensions (Venkatesh et al., 2016) do not assume an a-priori correlation across the explanatory latent variables, but rather view them as independent. Nevertheless, Di Pietro et al. (2015), Panagiotopoulos and Dimitrakopoulos (2018), and Zhang et al. (2019) found a positive association between ease-of-use and perceived usefulness in various case studies related to the adoption of new technologies such as on-line payment systems and automated vehicles. Similarly, our model shows a significant negative correlation between the perceived difficulty of use and the perceived performance expectancy including both information quality and trust in the shared information. Moreover, greater familiarity with the system is positively correlated with both performance expectancy measures. However, while previous studies found a reasonably high correlation between system usefulness and ease of use, the relationship between ease of use and effort expectancy is much lower. In fact, in line with the theoretical perspective, although significant, all the correlations are very low, and most are less than 0.2. The difference between the previous studies and the current study could be related to the definition of usefulness versus performance expectancy in that, while the former is user related, the latter is system related and hence the weaker correlation. Thus, we can conclude that the correlation across the latent variables does not impede the independence assumption of the original model in the current model.

Another interesting issue is the lack of correlation between the facilitating conditions and the other latent constructs. Notably, while the various versions of the UTAUT assume that 
facilitating conditions do not drive the other constructs (Venkatesh et al., 2016), it is theoretically and empirically plausible that policy, institutional, and environmental conditions would influence performance and effort expectancy as well as social influence. Such a correlation could generate indirect effects of the facilitating conditions in addition to the direct effect. Because this issue is important from the policy perspective, we have tested for a correlation between the facilitating condition of social media engagement and the remaining factors. According to the correlation matrix in Table 5, the correlations are statistically significant, but very low (less than 0.2). Thus, in our case study, indirect effects of social network engagement are limited. Presumably, the effect of facilitating conditions can only be evaluated when a change occurs in the facilitating conditions, for example with a before and after approach.

\begin{tabular}{|c|c|c|c|c|c|c|c|}
\hline & $\begin{array}{l}\text { Information } \\
\text { quality }\end{array}$ & $\begin{array}{l}\text { Familiarity } \\
\text { with the } \\
\text { system }\end{array}$ & $\begin{array}{l}\text { Perceived } \\
\text { difficulty of } \\
\text { use }\end{array}$ & $\begin{array}{l}\text { Self- } \\
\text { actualizatio } \\
\text { n by sharing }\end{array}$ & $\begin{array}{l}\text { Social } \\
\text { norms for } \\
\text { sharing }\end{array}$ & $\begin{array}{l}\text { Trust in } \\
\text { the shared } \\
\text { informatio } \\
n\end{array}$ & $\begin{array}{l}\text { Need for } \\
\text { personal } \\
\text { communic } \\
\text { ation }\end{array}$ \\
\hline $\begin{array}{l}\text { Information } \\
\text { quality }\end{array}$ & 1.0 & & & & & & \\
\hline Familiarity & $\begin{array}{c}0.029 \\
(2.308)\end{array}$ & 1.0 & & & & & \\
\hline $\begin{array}{l}\text { Perceived } \\
\text { difficulty of use }\end{array}$ & $\begin{array}{c}-0.034 \\
(-2.155)\end{array}$ & $\begin{array}{c}-0.043 \\
(-2.303)\end{array}$ & 1.0 & & & & \\
\hline $\begin{array}{l}\text { Self- } \\
\text { actualization by } \\
\text { sharing }\end{array}$ & $\begin{array}{c}0.034 \\
(2.133)\end{array}$ & $\begin{array}{c}0.061 \\
(3.262)\end{array}$ & $\begin{array}{c}-0.241 \\
(-13.531)\end{array}$ & 1.0 & & & \\
\hline $\begin{array}{l}\text { Social norms } \\
\text { for sharing }\end{array}$ & $\begin{array}{c}0.031 \\
(2.033) \\
\end{array}$ & $\begin{array}{c}0.063 \\
(3.509) \\
\end{array}$ & $\begin{array}{l}-0.238 \\
(-13.7) \\
\end{array}$ & $\begin{array}{c}0.236 \\
(13.035) \\
\end{array}$ & 1.0 & & \\
\hline $\begin{array}{l}\text { Trust in the } \\
\text { shared } \\
\text { information }\end{array}$ & $\begin{array}{c}0.021 \\
(1.473)\end{array}$ & $\begin{array}{c}0.014 \\
(0.844)\end{array}$ & $\begin{array}{c}-0.204 \\
(-11.617)\end{array}$ & $\begin{array}{c}0.184 \\
(10.098)\end{array}$ & $\begin{array}{c}0.196 \\
(10.83)\end{array}$ & 1.0 & \\
\hline $\begin{array}{l}\text { Need for } \\
\text { personal } \\
\text { communication }\end{array}$ & $\begin{array}{c}-0.005 \\
(-0.531)\end{array}$ & $\begin{array}{c}-0.022 \\
(-1.543)\end{array}$ & $\begin{array}{c}-0.057 \\
(-3.236)\end{array}$ & $\begin{array}{c}0.040 \\
(2.316)\end{array}$ & $\begin{array}{c}0.055 \\
(3.168)\end{array}$ & $\begin{array}{c}0.074 \\
(4.766)\end{array}$ & 1.0 \\
\hline $\begin{array}{l}\text { Social network } \\
\text { engagement }\end{array}$ & $\begin{array}{c}0.028 \\
(2.102)\end{array}$ & $\begin{array}{c}0.032 \\
(1.916)\end{array}$ & $\begin{array}{c}-0.175 \\
(-9.913)\end{array}$ & $\begin{array}{c}0.166 \\
(9.537)\end{array}$ & $\begin{array}{c}0.173 \\
(9.728)\end{array}$ & $\begin{array}{c}0.170 \\
(9.879)\end{array}$ & $\begin{array}{c}0.063 \\
(4.224) \\
\end{array}$ \\
\hline
\end{tabular}

Table 5: Estimated correlation matrix for the latent variables

\section{Discussion and conclusion}

The traditional practice of transit information provision considers a unidirectional information flow from the operators as active communicators of information to transit users as passive consumers. New travel information technologies consider a multi-directional information flow with travelers sharing sensory information, travel experience, and incident reports. These new collaborative exchange information platforms necessitate active user engagement for their success and long-term survival. The results of this study shed light on the motivational factors underlying intentions to share information rather than solely engaging in receiving information while using transit apps for the daily commute.

A possible argument hindering the development of collaborative transit apps is that good transit system quality may reduce the overall value of transit information consumption and sharing. Namely, if most of the benefit comes from arrival time information that is passively generated and distributed, then it may be questioned whether it is likely that passengers will make much effort in active sharing in a well-managed transit environment. The current study concerns high-quality and high-information use transport environments. A previous study in Copenhagen (Kaplan et al., 2017) shows that most respondents (60-70\%) perceived good transit 
service coverage, low crowding, and satisfactory travel times and reliability. It also shows that the most commonly used information sources are travel apps and on-line information (93.95\%), real-time information in vehicles or at stops (85.47\%), and Google Maps (81.60\%). In a recent survey in Innsbruck, Austria, 77\% of the respondents were satisfied with the transit system, $90 \%$ were satisfied with the network coverage, $80 \%$ considered the vehicle fleet as clean and comfortable, and 62\% were satisfied with the system reliability (Sarker et al., 2019). These values coincide with the IVB (Innsbruck Transport Authority) 2016 official customer survey, showing generally high satisfaction with the transit system. The current study shows that even under the conditions of an excellent quality transit system and high system quality assurance, $50-60 \%$ of the transit users have addressed the need to receive information and about $30-40 \%$ are willing to share information. Most interestingly, 34\% of the survey respondents were willing to share information related to the level of service including arrival times. Namely, our study shows that even in a well-managed system where travelers are satisfied with the level of service, one third of the transit users are willing to share information regarding their travel times. Consequently, user-based information should be an integral part of designing and operating a high-quality transit system, rather than being considered as merely a remedy for lack of information in a poor quality transit environment.

Another possible argument hindering the development of collaborative travel apps is that data passively generated by the operators, for example transit schedules via General Transit Feed Specification (GTFS), and travel-time data from the analysis of smart cards are deemed sufficient input for arrival time estimates in transit information apps and thus active sharing is needed less. However, actual transit operation may differ substantially from the expected schedules. The use of smart card data could be helpful as an augmented measure to estimate actual travel time, but the analysis of such data is always retroactive and thus can only be used for strategic planning (Wessels et al., 2017). Moreover, the use of multi-modal travel apps for booking and payment may render the smart card obsolete. Thus, active data sharing by users, either in the form of permission to track the phone or in messaging to other users, remains the sole source of real-time information. Pender et al. (2014) and Xu et al. (2018) provide extensive reviews of the value of crowdsourcing active information sharing on social media for traffic event detection and management. A possible direction for enhancing information sharing could involve the combination of active sharing based on passive crowd-sourcing information as suggested by Nunes et al. (2016) and our approach for user-based active information sharing. Adding app features that enable users to see their contribution in bettering LOS and RT information may contribute to strengthening information sharing based on performance expectancy and the users' own appreciation of their contribution. Currently, users in any travel information app are neither aware of their passive nor active contribution to improving the system. Increasing user awareness of their contribution to system improvement may generate strong user empowerment on the basis of community efficacy in inducing change.

For private entrepreneurs with a business model based on data mining of user data and voluntary data contributions, on the one hand, and advertisements of locations, activities, and products, on the other hand, a large user base is essential. Hence, a critical mass of users is important for the success and long-term survival of collaborative travel apps. An important question considering the development of collaborative transit apps is whether higher system engagement, manifested in higher transit use, is associated with higher willingness to share information. Farag and Lyons (2012) show that information consumption is lower for habitual, frequent, long-distance business and leisure trips. Hou and Chen (2013), Brakewood et al. 
(2014), and Dyrberg et al. (2015) show that for city trips habitual transit use is positively related to information consumption. Our study adds that more frequent transit use is not only related to information consumption, but also to the willingness to share information. However, much like Velasquez et al. (2018), who show that the link between transit use and information consumption is mediated through individual traits of technophile and time-saving skills which motivate the need for information, we show that the link between transit use and information sharing is mediated through system familiarity, perceived appreciation, and effort expectancy. Moreover, frequent transit use does not influence trust in the information provided, neither positively nor negatively. Possibly, the large variety of inner-city line combinations in comparison with the relatively limited inter-city line options motivates higher information needs (Kaplan et al., 2017) and thus higher willingness to share information. Hence, from the transit operators' and app developers' perspective, thus both enlarging the share of transit users and encouraging each user to become a frequent user are highly important for the collection of high-quality information. Possibly, embedding 'green travel loyalty' programs within real-time transit or multi-modal travel apps is the next step both towards increasing ridership and towards higher willingness to share information (Dastjerdi et al., 2019). Moreover, because becoming a 'green travel loyalty' member is related to trust in travel information technology and trip efficiency improvements in addition to social motivators, further research could look at sharing information and becoming a 'green travel loyalty member' as inter-related decisions.

For both entrepreneurs and transit operators, user engagement is as important as a large app user pool, and is considered an important challenge of the development of travel apps (Dickinson et al., 2015). Dickinson et al. (2015) identified poor app functionality as the main barrier to app use, with small monetary incentives being inefficient and counter-productive for user engagement. Technological barriers can be easily addressed by app developers, and monetary incentives are not only inefficient from the user perspective, but also from the policy perspective because of their high costs. Dickinson et al. (2015) also suggest using community champions as a promotional strategy, which could be temporarily beneficial, but cannot resolve long-term daily engagement. Our study suggests that upon resolving the functional barrier, user engagement remains unresolved from the technological perspective. Instead, for policy makers, our study shows that the key to user engagement should not be monetary but rather satisfy the higher-order needs of social recognition, user appreciation, and self-actualization. These are powerful motivators for app engagement. The results in our study add to the results found by Dastjerdi et al. (2019) that information sharing behavior (e.g. sharing $\mathrm{CO}_{2}$ savings and fitness, social network engagement, and helping others) is associated with greater intention to use a "green loyalty" program as a gamification element in the new multi-modal travel app for Copenhagen. The two studies show that gamification involving tokens of appreciation from other users and the transit authority could be useful to encourage users to use the app for information sharing. Thus, group games that are based on competition and collaboration among app users could be an idea for app developers to follow. Hence, further research should focus on the efficacy of collaborative travel gamification for information sharing in actual app use.

\section{Acknowledgement}

We thank three anonymous reviewers for their helpful comments on an earlier version of this manuscript. We also appreciate the COST (European Cooperation for Science and Technology) office for providing the opportunity of a Short Term Scientific Mission for this research cooperation within COST Action TUD 1305 on social networks and travel behavior. 


\section{Appendix 1}

Figure A1 shows parallel analysis to determine the number of factors. Table A1 shows the $\mathrm{KMO}$, factor loadings, and the communalities of the factor.

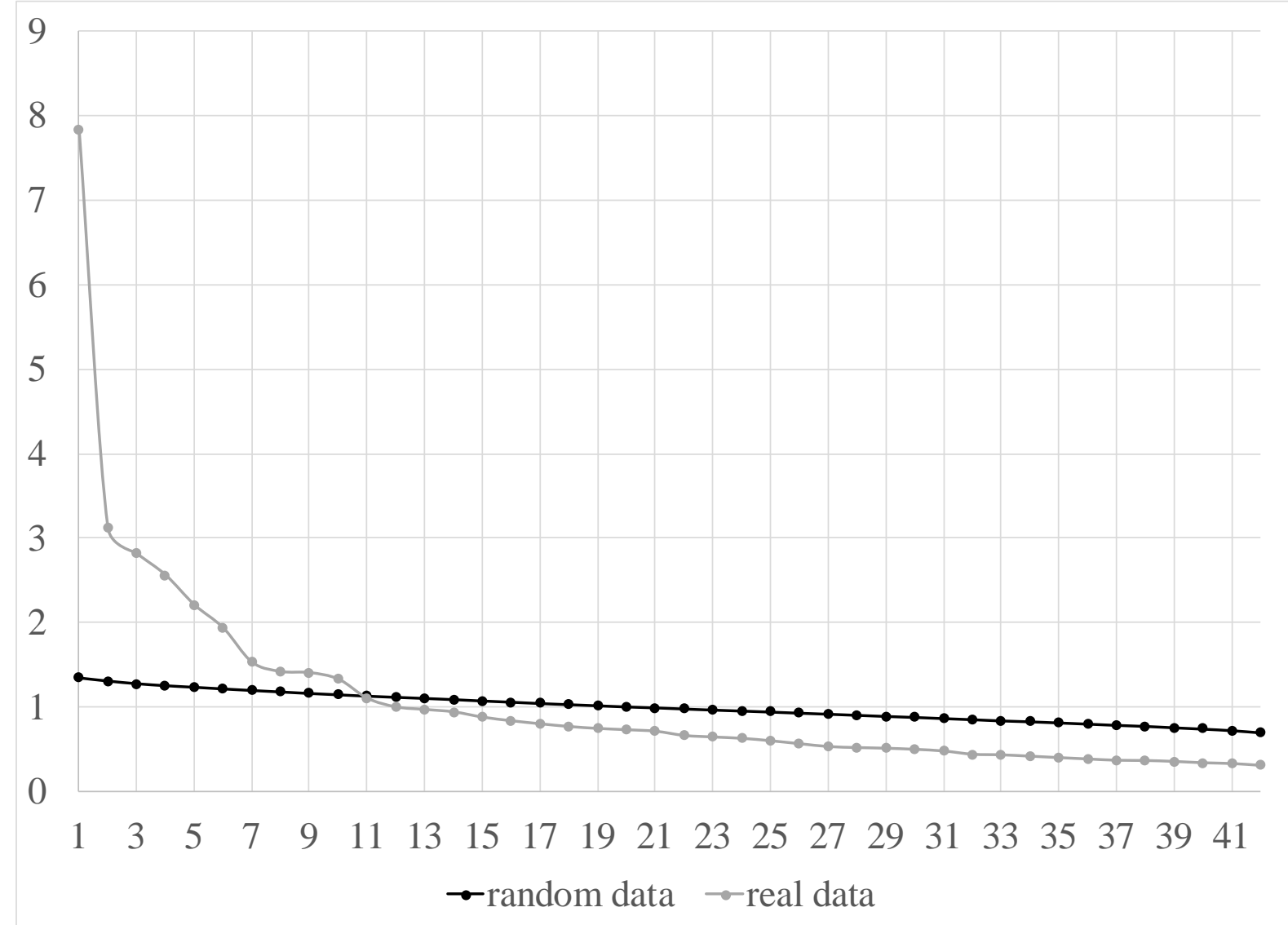

Figure A1: parallel analysis

\begin{tabular}{|l|c|c|c|}
\hline Information quality & KMO & $\begin{array}{c}\text { Factor } \\
\text { loadings }\end{array}$ & Communalities \\
\hline The travel time/waiting time information is reliable & 0.676 & 0.632 & 0.408 \\
\hline The information about delays/changes is reliable & 0.666 & 0.588 & 0.354 \\
\hline The information system provides efficient routes & 0.828 & 0.543 & 0.311 \\
\hline The information is clear and comprehensible & 0.720 & 0.643 & 0.470 \\
\hline The information is easy to find & 0.749 & 0.552 & 0.381 \\
\hline Familiarity & & & 0.380 \\
\hline The frequency of lines I need & 0.768 & 0.606 & 0.373 \\
\hline How to arrive at new destination & 0.779 & 0.605 & 0.461 \\
\hline Transit stops closest to my destination & 0.767 & 0.672 & 0.461 \\
\hline Timetable of modes that I use most & 0.771 & 0.649 & 0.277 \\
\hline The bus /train lines in my local area & 0.849 & 0.508 & \\
\hline Perceived difficulty of use & & & 0.218 \\
\hline It would be too time-consuming for me & 0.849 & 0.383 & 0.156 \\
\hline I would often forget to share important information & 0.889 & 0.356 & \\
\hline
\end{tabular}




\begin{tabular}{|c|c|c|c|}
\hline It would be too much effort for me & 0.875 & 0.448 & 0.314 \\
\hline $\begin{array}{l}\text { It would be difficult because I am often not online when } \\
\text { travelling }\end{array}$ & 0.705 & 0.346 & 0.191 \\
\hline $\begin{array}{l}\text { It would be difficult because my phone is often turned off } \\
\text { while travelling }\end{array}$ & 0.692 & 0.321 & 0.244 \\
\hline \multicolumn{4}{|l|}{ Self-actualization by sharing } \\
\hline I gladly help others by providing information & 0.919 & 0.735 & 0.588 \\
\hline Most people find the information I share useful & 0.899 & 0.694 & 0.523 \\
\hline $\begin{array}{l}\text { It gives me a good feeling to share information even if } \\
\text { people don't thank me }\end{array}$ & 0.930 & 0.759 & 0.629 \\
\hline $\begin{array}{l}\text { I share information so that others can benefit from my } \\
\text { experience }\end{array}$ & 0.918 & 0.785 & 0.669 \\
\hline It pleases me to be able to help others with information & 0.905 & 0.770 & 0.627 \\
\hline \multicolumn{4}{|l|}{ Social norms of sharing } \\
\hline Public transport users would appreciate it & 0.920 & 0.480 & 0.348 \\
\hline Public transport operators would appreciate it & 0.872 & 0.265 & 0.206 \\
\hline $\begin{array}{l}\text { People who are important to me would encourage me } \\
\text { to do it }\end{array}$ & 0.914 & 0.543 & 0.421 \\
\hline It would make me feel part of the user community & 0.928 & 0.564 & 0.540 \\
\hline It would expand my social network & 0.841 & 0.717 & 0.602 \\
\hline I would feel connected to other users & 0.848 & 0.688 & 0.591 \\
\hline \multicolumn{4}{|l|}{ Trust in the information provided } \\
\hline I also trust information from people who I do not know & 0.894 & 0.667 & 0.488 \\
\hline Other passengers usually provide trustworthy information & 0.889 & 0.648 & 0.469 \\
\hline $\begin{array}{l}\text { I trust information shared by my virtual social network } \\
\text { (e.g. Facebook friends) }\end{array}$ & 0.936 & 0.543 & 0.371 \\
\hline Arrival times, traffic congestion, and delays & 0.920 & 0.573 & 0.378 \\
\hline $\begin{array}{l}\text { Available seats (e.g. empty seats, space for bicycle / } \\
\text { pushchair) }\end{array}$ & 0.898 & 0.436 & 0.255 \\
\hline $\begin{array}{l}\text { Crowds during special events (e.g. football matches, } \\
\text { music events) }\end{array}$ & 0.909 & 0.574 & 0.361 \\
\hline Alternative routes (e.g. faster, cheaper) & 0.892 & 0.396 & 0.245 \\
\hline Answers to my specific questions to other users & 0.918 & 0.412 & 0.278 \\
\hline \multicolumn{4}{|l|}{ Old-fashioned communication } \\
\hline Face-to-face & 0.732 & 0.613 & 0.389 \\
\hline Voice phone calls & 0.620 & 0.772 & 0.598 \\
\hline Text messages & 0.747 & 0.651 & 0.452 \\
\hline \multicolumn{4}{|l|}{ Social network engagement } \\
\hline I read other people's posts online & 0.853 & 0.576 & 0.432 \\
\hline I post my opinions online & 0.814 & 0.748 & 0.608 \\
\hline I post if I do something interesting & 0.871 & 0.711 & 0.554 \\
\hline I share what other people post & 0.863 & 0.677 & 0.518 \\
\hline I comment and like others' posts & 0.863 & 0.726 & 0.589 \\
\hline
\end{tabular}

Table A1: Exploratory factor analysis results 


\section{References}

Amaya, M., R. Cruzat, and M.A. Munizaga, 2018. Estimating the residence zone of frequent transit users to make travel pattern and time use analysis. Journal of Transport Geography, 66, 330-339.

Andersson, A., L. W. Hiselius, and E. Adell, 2018. Promoting sustainable travel behaviour through the use of smartphone applications: A review and development of a conceptual model. Travel Behavior and Society, 11, 52-61.

Attard, M., M. Haklay and C. Capineri, 2016. The Potential of Volunteered Geographic Information in Future Transport Systems. Urban Planning, 1, 6-19.

Belk, R., 2014. You are what you can access: Sharing and collaborative consumption online. Journal of Business Research, 67, 1595-1600.

Ben-Elia, E., and E. Avineri, 2015. Response to Travel Information: A Behavioural Review, Transport Reviews, 35, 352-377.

Berger, M., and M. Platzer, 2015. Field evaluation of the smartphone-based travel behaviour data collection app “SmartMo”. Transportation Research Procedia, 11, 263-279.

Boelhouwer, J., G. Kraaykamp, and I. Stoop, 2016. Trust, life satisfaction and opinions on immigration in 15 European countries. The Netherlands Institute for Social Research, The Hague, 17-18.

Bolton, R.N., A. Parasuraman, Ankie Hoefnagels, N. Migchels, S. Kabadayi, T. Gruber, Y. Komarova-Loureiro, and D. Solnet, 2013. Understanding Generation Y and their use of social media: a review and research agenda. Journal of Service Management, 24, 245-267.

Brabham, D. C., 2012. Motivations for participation in a crowdsourcing application to improve public engagement in transit planning, Journal of Applied Communication Research, 40, 307-328. 
Brakewood, C., S. Barbeau, K. Watkins, 2014. An experiment evaluating the impacts of realtime transit information on bus riders in Tampa, Florida, Transportation Research Part A, 69, 409-422.

Carrel, A., S.C. Peter, R.G. Mishalani, R. Sengupta, J.L. Walker, 2015. Quantifying transit travel experiences from the users' perspective with high-resolution smartphone and vehicle location data: Methodologies, validation, and example analyses, Transportation Research Part C, 58, 224-239.

Chaves, A.P., Steinmacher, I., and V. Vieira, 2011. Social networks and collective intelligence applied to transitation systems: A survey. VIII SBSC, 16-23.

Chatterjee, K., P. Goodwin, T. Schwanen, Clark, B., Jain, J., Melia, S., Middleton, J., Plyushteva, A., Ricci, M., Santos, G. and Stokes, G., 2018. Young People’s Travel - What’s Changed and Why? Review and Analysis. Report to Department for Transport. UWE Bristol, UK.

Chorus, C., J.L. Walker, and M. Ben-Akiva, 2013. A joint model of travel information acquisition and response to received messages. Transportation Research Part C, 26, 61-77. Chorus, C.G., T.A. Arentze, H.J.P. Timmermans, 2009. Traveler compliance with advice: A Bayesian utilitarian perspective. Transportation Research Part E, 45, 486-500.

Chorus, C. G., T. A. Arentze, H. J. P. Timmermans, E. J. E. Molin, and B. Van Wee, 2007. Travelers' Need of Information in Traffic and Transit: Results from a Web Survey, Journal of Intelligent Transportation Systems, 11, 57-67.

Costa, P.M., T. Fonte, A. A. Nunes, M.C. Ferreira, V. Costa, T. Galvao Dias, J.L. Borges, and J. Falcao e Cunha, 2016. Application of collaborative information exchange. Transportation Research Procedia, 14, 2016, 1201-1210.

Cottrill, C., P. Gault, G. Yeboah, J.D. Nelson, J. Anable, and Budd, T., 2017. Tweeting Transit: An examination of social media strategies for transport information management during a large event. Transportation Research Part C, 77, 421-432. 
Dastjerdi Mehdizadeh, A., S. Kaplan, J. A. Silva, O. A. Nielsen, and F.C. Pereira, 2019. Participating in environmental loyalty program with a real-time multimodal travel app: User needs, environmental and privacy motivators. Transportation Research Part D, 67, 223243.

Dickinson, J. E., T. Cherrett, J. F. Hibbert, C. Winstanley, D. Shingelton, N. Davis, Norgate, S., and C. Speed, 2015. Fundamental challenges in designing a collaborative travel app. Transport Policy, 44, 28-36-20.

Di Pietro, L., R. Guglielmetti Mugion, G. Mattia, M.F. Renzi, M. Toni, 2015. The Integrated Model on Mobile Payment Acceptance (IMMPA): An empirical application to public transport. Transportation Research Part C 56, 463-479.

Dyrberg, M. B., C. Christensen, M. Anderson, O.A. Nielsen, C. G. Prato, 2015. Transfer attributes in route choice models for public transport passengers, European Association for Research in Transportation Conference, 9-11 September, Copenhagen.

Farag, S., \& Lyons, G. 2012. To use or not to use? An empirical study of pre-trip public transport information for business and leisure trips and comparison with car travel. Transport Policy, 20, 82-92.

Farkas, K., G. Feher, A. Benczur, and C. Sidlo, 2015. Crowdsensing based transit information service in smart cities. IEEE Communications Magazine, 158-165.

Filippi, F., G. Fusco, and U. Nanni, 2013. User empowerment and advanced transit solutions. Procedia - Social and Behavioral Sciences, 87, 3-17.

Fielding, M., 2004, 'New Wave’ Student Voice and the Renewal of Civic Society, London Review of Education, 2, No. 3.

Gadziński, J., 2018, Perspectives of the use of smartphones in travel behaviour studies: Findings from a literature review and a pilot study, Transportation Research Part C, 88, 74-86. 
Grothenhuis, J.W., B.W. Wiegmans, and P. Rietveld, 2007. The desired quality of integrated multimodal travel information in transit: Customer needs for time and effort savings. Transport Policy, 14, 27-38.

Gu, Y., Q. Zhen, and F. Cheng, 2016. From Twitter to detector: Real-time traffic incident detection using social media data. Transportation Research Part C, 67, 321-342.

Hara, K., S. Azenkot, M. Campbell, C.L. Bennett, V. Le, S. Pannella, R. Moore, K. Minckler, R.H. Ng, and J.E. Froehlich, 2015. Improving public transit accessibility for blind riders by crowdsourcing bus stop landmark locations with Google street view: An Extended Analysis. Transactions on Accessible Commuting, 6, 1-23.

Heiskala, M., J.P. Jokinen, and M. Tinnila, 2016. Crowdsensing-based transportation services - An analysis from business model and sustainability viewpoints. Research in Transportation Business \& Management, 18, 38-48.

Hounsell, N.B., B.P. Shrestha, M. McDonald, and A. Wong, 2016. Open data and the needs of older people for transit information. Transportation Research Procedia, 14, 4334-4343.

Hou, X. and X. Chen, 2013. Analysis of Urban Public Transit Information Requirements in China by Web-based Survey, Procedia - Social and Behavioral Sciences, 96, 1522 - 1527

Kaplan, S., M. Moraes-Monterio, M.K. Anderson, O.A. Nielsen, and E. Madeiros-dos-Satos, 2017. The role of information systems in non-routine transit use of university students: Evidence from Brazil and Denmark. Transportation Research Part A, 9, 34-48.

Khoo, H.L., and K.S. Asitha, 2016. User requirements and route choice response to smart phone traffic applications. Travel Behaviour and Society, 3, 59-70.

Kim, S., and T. H. Baek, 2018. Examining the antecedents and consequences of mobile app engagement. Telematics and Informatics, 35, 148-158.

Kim, J., S. Rasouli, and H. Timmermans, 2014. Hybrid choice models: Principles and recent progress incorporating social influence and nonlinear utility functions. Procedia Environmental Sciences, 22, 20-34. 
Kimmerle, J., and U. Cress, 2013. The impact of cognitive anchors on information-sharing behavior. Cyberpsychology, Behavior, and Social Networking, 16, 45-49.

Lindenberg, S., and L. Steg, 2007. Normative, gain and hedonic goal frames guiding environmental behavior. Journal of Social Issues, 63, 117-137.

Liu, Y., P. Bansal, R. Daziano, S. Samaranayake, 2019. A framework to integrate mode choice in the design of mobility-on-demand systems, https://doi.org/10.1016/j.trc.2018.09.022, in press.

Lyu, Y., C.Y. Chow, V.C.S. Lee, J.K.Y. Ng, Y. Li, J. Zeng, 2019. CB-Planner: A bus line planning framework for customized bus systems. Transportation Research Part C 101, 233253.

Miller, H.J., 2013. Beyond sharing: cultivating cooperative transportation systems through geographic information science. Journal of Transport Geography, 31, 296-308.

Molin, E.J.E., and H.P. Timmermans, 2006. Traveler expectations and willingness-to-pay for web-enabled transit information services. Transportation Research Part C, 14, 57-67.

Moráis, N., F. Sobral, S. Ferreira, T. Gouveia and C. Gomes, 2017. Trends in online consumption and sharing of content by higher education students, International Symposium on Computers in Education, 1-6. DOI 10.1109/SIIE.2017.8259664.

Moovit, 2019, viewed 27 January 2019, < https://www.company.moovit.com/>.

Nandan, N., A. Pursch, and X. Zhe, 2014. Challenges in crowdsourcing real-time information for transitation. IEEE 15th International Conference on Mobile Data Management, 67-72. DOI 10.1109/MDM.2014.70.

Newton, K., 2002. Trust, social capital, civil society and democracy, International Political Science Review, 22, 201-214.

Nitsche, P., P. Widhalm, S. Breuss, N. Brändle and P. Maurer, 2013. Supporting large-scale travel surveys with smartphones - A practical approach, Transportation Research Part C, 43, 212-221 
Nunes, A.A., T. Galvão Dias, and J. Falcão e Cunha, 2014. Urban transit service co-creation: leveraging passenger’s knowledge to enhance travel experience. Procedia - Social and Behavioral Sciences, 111, 577-585.

Nunes, A.A., T. Galvão Dias, Zegras, C. and J. Falcão e Cunha, 2016. Temporary user-centered networks for transport systems. Transportation Research Part C 62, 55-69.

Panagiotopoulos, I., G. Dimitrakopoulos, 2018. An empirical investigation on consumers’ intentions towards autonomous driving. Transportation Research Part C 95, 773-784.

Pelletier, M.P., M. Trepanier, C. Morency, 2011. Smart card data use in public transit: A literature review. Transportation Research Part C, 19, 557-568.

Pender, B., G. Currie, A. Delbosc, N. Shiwakoti (2014) Social Media Use during Unplanned Transit Network Disruptions: A Review of Literature, Transport Reviews, 34:4, 501-521.

Schmitz, C., S. Bartsch, and A. Meyer, 2016. Mobile App Usage and Its Implications for Service Management - Empirical Findings from German Transit. Procedia - Social and Behavioral Sciences, 224, 230-237.

Shaheen, S., A. Cohen, and E. Martin, 2017. Smartphone app evolution and early understanding from a multimodal app user survey. Lecture Notes in Mobility, 149-164. DOI 10.1007/9783-319-51602-8_10.

Sørvoll, J., and B. Bengtsson, 2018. Mechanisms of Solidarity in Collaborative Housing - The Case of Co-operative Housing in Denmark 1980-2017, Housing, Theory and Society, 1-17. Sun, Z., Z. Ji, P. Zhang, C. Chen, X. Qian, X. Du, Q. Wan, 2017. Automatic labeling of mobile apps by the type of psychological needs they satisfy. Telematics and Informatics, 34, 767778.

Sujithamrak, S. and T. Lam, 2005. Relationship between customer complaint behavior and demographic characteristics: A study of hotel restaurants' patrons, Asia Pacific Journal of Tourism Research, 10:3, 289-307, DOI: 10.1080/10941660500309697 
Sarker, R., S. Kaplan, M. Mailer and H.P. Timmermans, 2019. Applying affective event theory to explain transit users' reactions to service disruptions. $98^{\text {th }}$ Annual Meeting of the Transportation Research Board, session 1636, 13-17 January, Washington.

Tomasic, A., J. Zimmerman, A. Steinfeld and Y. Huang, 2014. Motivating contribution in a participatory sensing system via Quid-Pro-Quo. CSCW, Baltimore, USA, 979-988. DOI.ORG/10.1145/2531602.2531705.

Venkatesh, V., M. G. Morris, G. B. Davis and F. D. Davis, 2003. User acceptance of information technology: toward a unified view. Management Information Systems Quarterly, 27, 425-478.

Venkatesh, V., J.Y.L Thong, X. Xu, 2016 Unified Theory of Acceptance and Use of Technology: A Synthesis and the Road Ahead. Journal of the Association for Information systems 17(5), pp. 328-376.

Velazquez, G., S. Kaplan, and M. Andreas, 2018. Ex-Ante and Ex-Post Evaluation of a New Transit Information App: Modeling Use Intentions and Actual Use. Transportation Research Record, 2672, 56-65.

Wessel, N., J. Allen, S. Farber, 2017. Constructing a routable retrospective transit timetable from a real-time vehicle location feed and GTFS. Journal of Transport Geography 62, pp. 92-97.

Xu, S., S. Li., Wen, R., 2018. Sensing and detecting traffic events using geosocial media data: A review. Computers, Environment and Urban Systems 72 146-160.

Yao, B., P. Hu, X. Lu, J. Gao, M. Zhang, 2014. Transit network design based on travel time reliability. Transportation Research Part C 46, pp. 83-97.

Yan, X., J. Levine, X. Zhao, 2018. Integrating ride-sourcing services with public transit: An evaluation of traveler responses combining revealed and stated preference data. Transportation Research Part C, in press, https://doi.org/10.1016/j.trc.2018.07.029. 
Yildirimoglu, M., J. Kim, 2018. Identification of communities in urban mobility networks using multi-layer graphs of network traffic. Transportation Research Part C 89, 254-267.

Zhang, C., T.L. Liu, H.J. Huang and J. Chen, 2018. A cumulative prospect theory approach to commuters' day-to-day route-choice modeling with friends' travel information. Transportation Research Part C, 86, 527-548.

Zhang, T., D. Tao, X. Qua, X. Zhang, R. Lin, W. Zhang, 2019. The roles of initial trust and perceived risk in public's acceptance of automated vehicles. Transportation Research Part C 98, 207-220. 